\title{
BMJ Open Barriers to early presentation of self-discovered breast cancer in Singapore and Malaysia: a qualitative multicentre study
}

Jennifer NW Lim, ${ }^{1}$ Barbara Potrata, ${ }^{2}$ Leonardo Simonella, ${ }^{3}$ Celene WQ Ng, ${ }^{4}$ Tar-Ching Aw, ${ }^{5}$ Maznah Dahlui, ${ }^{6}$ Mikael Hartman, ${ }^{3,4}$ Rifhan Mazlan, ${ }^{7}$ Nur Aishah Taib ${ }^{7}$

To cite: Lim JNW, Potrata B, Simonella L, et al. Barriers to early presentation of self-discovered breast cancer in Singapore and Malaysia: a qualitative multicentre study. BMJ Open 2015;5:e009863. doi:10.1136/bmjopen-2015009863

- Prepublication history for this paper is available online. To view these files please visit the journal online (http://dx.doi.org/10.1136/ bmjopen-2015-009863).

Received 31 August 2015 Revised 23 November 2015 Accepted 24 November 2015

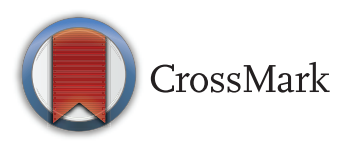

For numbered affiliations see end of article.

Correspondence to Jennifer NW Lim; Jennifer.lim@anglia.ac.uk

\section{ABSTRACT}

Objective: To explore and compare barriers to early presentation of self-discovered breast cancer in Singapore and Malaysia.

Design: A qualitative interview study with thematic analysis of transcripts.

Participants: 67 patients with self-discovered breast symptoms were included in the analysis. Of these, $36 \%$ were of Malay ethnicity, $39 \%$ were Chinese and $25 \%$ Indian, with an average age of 58 years (range 24-82 years). The number of women diagnosed at early stages of cancer almost equalled those at advanced stages. Approximately three-quarters presented with a painless lump, one-quarter experienced a painful lump and 10\% had atypical symptoms.

Setting: University hospital setting in Singapore and Malaysia.

Results: Patients revealed barriers to early presentation not previously reported: the poor quality of online website information about breast symptoms, financial issues and the negative influence of relatives in both countries, while perceived poor quality of care and services in state-run hospitals and misdiagnosis by healthcare professionals were reported in Malaysia. The pattern of presentation by ethnicity remained unchanged where more Malay delayed help-seeking and had more advanced cancer compared to Chinese and Indian patients.

Conclusions: There are few differences in the pattern of presentation and in the reported barriers to seek medical care after symptom discovery between Singapore and Malaysia despite their differing economic status. Strategies to reduce delayed presentation are: a need to improve knowledge of disease, symptoms and causes, quality of care and services, and quality of online information; and addressing fear of diagnosis, treatment and hospitalisation, with more effort focused on the Malay ethnic group. Training is needed to avoid missed diagnoses and other factors contributing to delay among health professionals.

\section{Strengths and limitations of this study}

- This was the first qualitative study to explore factors influencing presentation of selfdiscovered breast symptoms for medical care in Singapore.

- It was also the first large, qualitative study comparing help-seeking behaviour between Singapore (a high-income country with national breast screening and Malaysia (a middle-income country without national screening) where multiethnic societies share common beliefs, cultural practices and religions.

- Our study presented the latest data from both country. Previous studies used patient data dated up to 2007. Comparing the findings of previous studies, we found similar patterns of presentation by country and ethnicity and many barriers. We also found barriers that were not previously reported.

- Our findings in Malaysia have limited generalisation within the country. However, it is possible to generalise our findings in Singapore given the equitable distribution of resources within the country.

\section{INTRODUCTION}

As it does in many countries, breast cancer remains the most common female cancer in Singapore and Malaysia. Singapore has among the highest breast cancer incidence in Asia, with an age-standardised rate (ASR) of 54.9 per 100000 women/year ${ }^{1}$; Malaysia has an ASR of 38.7 per 100000 women/ year. $^{2}$

Singapore and Malaysia are neighbouring countries in Southeast Asia; the former being a high-income economy while the latter, a middle-income, developing country. Singapore has a population-based mammographic screening programme, BreastScreen 
Singapore, implemented in 2002. BreastScreen Singapore, available to women above 40 years old, is a subsidised fee-for-service facility. ${ }^{3}$ Malaysia adopts an opportunistic screening strategy: only women identified as having a high risk of breast cancer based on presenting symptoms or presence of risk factors such as family history of breast cancer are offered mammography screening. Annual clinical breast examination is provided for women undertaking cervical screening; and breast self-examination (BSE) is taught on request in the wellness, maternal and child health, and government outpatient clinics. ${ }^{4}$

The two countries share three dominant ethnic groups, namely, Chinese, Malay and Indian, with many similarities in religion, culture and beliefs. In Singapore, $75 \%$ of its 5.5 million population are Chinese, $14 \%$ Malay and 9\% Indian. Malaysia has a population of 30.4 million; Malays form the largest ethnic group (54\%) followed by $26 \%$ Chinese and $8 \%$ Indian. Substantial variation related to breast cancer was observed among the ethnic groups in the two countries, with the highest ASR in the Chinese group, followed by the Indian and Malay groups. ${ }^{5}{ }^{6}$ Larger tumour size and later stages at presentation were associated with being Malay compared to being Chinese, and, to a lesser extent, with being Indian. ${ }^{78}$

Advanced breast cancer is common, with Malaysia having a higher incidence than Singapore. In a cohort of 5471 patients in the Singapore-Malaysia Breast Cancer Hospital-based Registry (1995-2007), 22.3\% of patients in Malaysia had stage 3 compared to $14.4 \%$ in Singapore, and $10.8 \%$ vs $7.9 \%$ had stage 4 , respectively. ${ }^{7}$ Many attributed the lower incidence of later cancer in Singapore to the advanced healthcare facilities, higher awareness of disease, and good access to care and services in the country, with the opposite being true of Malaysia; ${ }^{7-9}$ but this has neither been confirmed nor fully investigated.

Quantitative research methods dominate the study of presentation and delayed help-seeking for breast cancer; focusing on mapping incidences and stages of cancer at diagnosis, establishing the relationship between survival outcomes and duration of delays, and knowledge of breast cancer and demographic attributes. Four systematic reviews were performed between 1999 and 2014, to examine factors influencing early presentation, diagnosis and breast cancer care and, of the 60 included studies, 6 were qualitative and 1 was a mixed methods study. ${ }^{10-13}$ Unlike quantitative research, qualitative research provides in depth explanations and contextual information crucial to understanding attitudes, decision-making processes, behaviours, concerns, motivations, culture or lifestyles, as well as in generating ideas for new strategies, interventions or theories. It is therefore an appropriate approach to study barriers to early presentation and diagnosis for illness. No qualitative study has yet investigated help-seeking behaviour for breast cancer in Singapore, nor compared presentation between the two countries despite their common ethnicity, cultural practices and beliefs.

Existing reviews conducted in developed countries ${ }^{10} 13$ and developing countries, ${ }^{11}{ }^{14}$ showed that late presentation and diagnosis were more likely to be patient related than provider related. Older age had a high association with delay by patients, ${ }^{10}{ }^{11}$ while younger age was associated with delay in diagnosis by providers for symptoms other than a breast lump. ${ }^{10}$ Lower education level, ${ }^{11}{ }^{12}$ having a family history of breast cancer ${ }^{11}$ and lower income status, ${ }^{12}$ were common factors preventing earlier presentation for breast cancer. Poor symptom and risk factor knowledge; fear of detecting breast abnormality and cancer treatments; partner abandonment; embarrassment in disclosing symptoms to healthcare professionals (HCPs); and taboo and stigmatism, all contributed to delayed help-seeking. ${ }^{13}$ Overall, the findings of these reviews showed that delayed presentation and help-seeking for breast cancer are contextual, and tailored strategies are needed to promote early presentation.

This paper presents the qualitative findings and comparative analysis of help-seeking behaviour on symptom discovery between Singapore and Malaysia. It is part of a larger study exploring the factors affecting breast cancer presentation in Southeast Asia and the Middle East, coordinated by the UK-Southeast Asia-Middle East (UK-SEA-ME) network. ${ }^{14}$

\section{METHODS}

\section{Study design and participants}

Women diagnosed with breast cancer in all stages and at any age, were recruited in 2008 and 2012, using a purposive sampling approach. In both countries, women were recruited from the dominant ethnic groupsMalay, Chinese and Indian. Potential participants who were diagnosed within 6 months of their cancer journey were identified from hospital databases at the National University Hospital Singapore (NUH) and University of Malaya Medical Centre (UMMC) in Kuala Lumpur, by their clinical team.

They were approached for participation during their regular (outpatient) clinical appointments by their clinical team directly and provided an information package to read. The research team contacted those interested, to arrange a meeting. The researchers further explained the study, informed patients that theirs was voluntary participation and that they had the right to withdraw at any time without their standard of care being affected, and obtained consent, before interviews took place.

\section{Data collection: interview guide and interviewing process}

We used a standard study protocol and topic guide covering topics on lay understanding of breast cancer, knowledge and awareness of symptoms, symptom interpretation, experience and behaviour, in their cancer journey from symptom discovery to treatment. Data were 
collected through face-to-face interviews (between 45 and $90 \mathrm{~min}$ ) at a time and place, and in a language of the patients' preference, after written informed consent was obtained. All interviews were audiotaped and transcribed verbatim, and non-English (Chinese, Indian and Malay language) transcripts were translated into English for analysis.

\section{Data analysis}

Main concepts and themes within the data were identified through a combination of open coding and thematic analysis. ${ }^{15} 16$ This involves reading and re-reading individual transcripts, and line-by-line coding of each transcript, followed by the organisation of these codes into recurring major themes and constructs at country level by JNWL, CWQN, LS and NAT, and the findings were presented in a network meeting in July 2013. Further comparative analysis was performed by JNWL and BP, to examine between countries differences and similarities, and to achieve data saturation.

\section{RESULTS}

Eighty-six patients completed the study: 46 in Malaysia and 40 in Singapore. In Singapore, we extended the data collection period from 6 to 9 months in order to achieve the number required and a response rate of at least $75 \%$. There was no withdrawal from the participation in this study and all patients were happy to talk about their breast cancer experience. Two participants were interviewed in the presence of a relative.

Overall, the proportion of participants recruited by ethnicity (Malay, Chinese and Indian) was representative of the multiethnic populations in both countries (table 1). Of these, 67 were included in the analysis; 18 excluded (4 for poor recording and 5 Singaporean and 9 Malaysian women were diagnosed following a mammography or regular health check).

There were $32(48 \%)$ participants aged 50 years or younger and the remaining $52 \%$ were over 50 years of age (average age $=58$ years; range 24-82 years). In Singapore, more participants were in the younger group. The majority $(79 \%)$ were married while $10(15 \%)$ were single.

'Discovering a lump' was the common relevant first symptom. Three-quarters of the participants (50) discovered a painless lump, and 10 women (15\%) experienced pain accompanying a lump. Seven women (10\%) had rare symptoms such as swelling or change in breast shape, rashes on the breast, inverted nipple, chest tightness, tingling pain in the breast, itchiness and a soft gel-like cyst on the nipple. Women often discovered these symptoms by chance while dressing or bathing.

The number of patients with early-stage breast cancer (S1 and S2) almost equalled those diagnosed at advanced stages (S3 and S4). Within country, more women in Malaysia had advanced stage cancer and higher tumour size (T) than in Singapore (table 1).

\begin{tabular}{|c|c|c|c|}
\hline Country & Singapore & Malaysia & Total \\
\hline Participants (N) & 31 & 36 & 67 \\
\hline \multicolumn{4}{|l|}{ Ethnicity } \\
\hline Chinese & 16 & 10 & 26 \\
\hline Malay & 8 & 16 & 24 \\
\hline Indian & 7 & 10 & 17 \\
\hline \multicolumn{4}{|l|}{ Age groups (years) } \\
\hline$\leq 50$ & 17 & 15 & 32 \\
\hline$>50$ & 14 & 21 & 35 \\
\hline \multicolumn{4}{|l|}{ Marital status } \\
\hline Married & 22 & 31 & 53 \\
\hline Widowed & 2 & 1 & 3 \\
\hline Divorced/separated & 0 & 1 & 1 \\
\hline Single & 7 & 3 & 10 \\
\hline \multicolumn{4}{|l|}{ Presenting symptoms } \\
\hline Painless lump & 23 & 27 & 50 \\
\hline Painful lump & 5 & 5 & 10 \\
\hline Atypical symptoms & 3 & 4 & 7 \\
\hline \multicolumn{4}{|l|}{ Stage at diagnosis } \\
\hline $\begin{array}{l}\text { Early stages } \\
\text { (S1 and S2) }\end{array}$ & 17 & 17 & 34 \\
\hline $\begin{array}{l}\text { Advanced stages } \\
\text { (S3 and S4) }\end{array}$ & 14 & 19 & 33 \\
\hline \multicolumn{4}{|l|}{ Tumour size (T) } \\
\hline $\mathrm{T} 1(\leq 2 \mathrm{~cm})$ & 7 & 12 & 19 \\
\hline T2 $(>2 \mathrm{~cm}$ but $>5 \mathrm{~cm})$ & 19 & 4 & 23 \\
\hline $\begin{array}{l}\text { T3 ( }>5 \mathrm{~cm} \text {, no extension } \\
\text { to chest wall) }\end{array}$ & 2 & 10 & 12 \\
\hline $\begin{array}{l}\text { T4 (any size with } \\
\text { extension to chest wall } \\
\text { and or skin) }\end{array}$ & 3 & 10 & 13 \\
\hline
\end{tabular}

\section{KNOWLEDGE AND PERCEIVED CAUSES OF BREAST CANCER}

Women were asked if they knew about breast cancer prior to their experience. All but three women said they had heard of breast cancer and knew some of the symptoms, especially a breast lump, but they did not know the causes and treatment. A couple of women also talked about their fatalistic views of cancer and breast cancer (table 2).

On perceived causes of cancer, women in both countries shared four common themes: diet such as fast food, red meat, fried food and hawker stall food; and family history, stress, and chemical and external environmental factors. Consumption of food seasoning (monosodium glutamate) used in restaurants and food stalls, pesticide used in agriculture and vaccination of farm animals, were believed to cause chemical build-up in the body and thus, breast cancer. One Malaysian woman said that chemicals absorbed through the skin, such as through frequent and prolonged use of nail varnish, caused her breast cancer. These women blamed long working hours as having caused their breast cancer. Some participants perceived that only women with large breasts had a high risk of breast cancer. Lack of breast feeding and milk 
Table 2 Perceived causes of breast cancer

\begin{tabular}{ll}
\hline Perceived causes of breast cancer & Country \\
\hline Diet (red meat, fried food, fast food, hawker stall food) & Singapore, Malaysia \\
Family history of cancer & Singapore, Malaysia \\
Stress & Singapore, Malaysia \\
Chemical/external influence (pesticide used for vegetables/fruits, antibody injection for farm & Singapore, Malaysia \\
animals, nail polish) & \\
Long working hours, with insufficient rest & Singapore, Malaysia \\
Breast feeding (lack of breast feeding; and milk clot due to breast feeding) & Singapore, Malaysia \\
Large breast & Malaysia \\
Old age & Singapore \\
\hline
\end{tabular}

clots after breast feeding were also believed to have developed into cancer. Younger women also thought that breast cancer was a condition confined mainly to older women.

\section{PRESENTATION OF SYMPTOMS BY COUNTRY AND ETHNICITY}

An interval of $<3$ months between symptom discovery and first presentation for medical care is defined as early presentation, and 3 months and over as late/ delayed presentation. After experiencing breast symptoms, over half of the participants (54\%) in this study presented early while the rest presented late $(46 \%)$ (table 3). Within country, there were more early presenters in Singapore $(65 \%)$ than in Malaysia $(44 \%) ; 35 \%$ of Singaporean participants delayed help-seeking, with $56 \%$ doing so among the Malaysian patients.

Table 3 also shows ethnic difference in terms of presentation. Sixty-four per cent of Chinese patients and $67 \%$ of Indian patients presented early compared to $33 \%$ of Malay patients. Two-thirds of Malay patients presented 3 months or later after symptom discovery.

Table 3 Early and late presentation, by country, for self-discovered symptom

\begin{tabular}{llll}
\hline $\begin{array}{l}\text { Interval between } \\
\text { symptom discovery } \\
\text { to presentation }\end{array}$ & Singapore & Malaysia & Total \\
\hline $\begin{array}{l}\text { Early presentation } \\
\text { Late/delayed }\end{array}$ & $20(65 \%)$ & $16(44 \%)$ & $36(54 \%)$ \\
$\begin{array}{l}\text { presentation } \\
\text { Early presentation }\end{array}$ & $11(35 \%)$ & $20(56 \%)$ & $31(46 \%)$ \\
$\quad$ Chinese & 12 & & \\
$\quad$ Malay & 3 & 4 & $16(64 \%)$ \\
$\quad$ Indian & 5 & 5 & $8(33 \%)$ \\
Late/delayed presentation & 7 & $12(67 \%)$ \\
$\quad$ Chinese & 4 & 5 & $9(36 \%)$ \\
$\quad$ Malay & 5 & 11 & $16(67 \%)$ \\
$\quad$ Indian & 2 & 4 & $6(33 \%)$ \\
Total & 31 & 36 & 67 \\
\hline
\end{tabular}

\section{WHAT LED TO EARLY PRESENTATION?}

Patients from both countries had similar reasons for early presentation for medical attention, namely BSE, knowledge of disease and role of relatives. Patients who were aware of breast cancer and performed regular BSE tended to seek immediate medical advice. In both countries, relatives played a positive role in encouraging and facilitating early help; children immediately brought their parent to the clinic and husbands told wives to seek medical attention 'immediately'.

\section{WHAT LED TO LATE PRESENTATION AND DIAGNOSIS?}

Women who delayed help-seeking in both countries shared similar barriers to help-seeking after symptom discovery (table 4). Misdiagnosis was reported in Malaysia.

Table 4 Barriers to early presentation for self-discovered symptoms

\section{Themes (reasons for delaying} or lateness)

\section{Country}

- Symptom interpretation: symptoms interpreted as signs of menstruation and breast feeding, lumpy breast

Malaysia and Singapore

- Information from online resources

- Attribution of symptoms to cancer: rare symptoms (pimple, soft gel patch, scar) expected to be simple explanation

- Fear of diagnosis and treatment due to fatalistic view of 'cancer' and poor knowledge of treatment

- Fear of hospitalisation

- Denial

- Preference for alternative and traditional medicine as the first-line treatment

- Busy with holiday, festivals, weddings

- Financial issue

- Misinformed by relatives

- Cultural (stigma) and marriage issues

- Fated because of a family history of cancer

Misdiagnosis by healthcare professional Malaysia 


\section{Symptom interpretation}

Ten women experienced pain/tenderness in their breast and they talked about their initial beliefs about their symptoms, and how they felt that their symptoms were due to breast feeding, menstruation or a previous experience.

I mistook pain in breast for breastfeeding. I told my sister and she said it must be breastfeeding. I only visited the doctor when the pain became unbearable. (Malaysia, Chinese, 35 years, T3, S3)

It was just another clot in my breast, I thought. I had two benign lumps. This third time, I assumed it would also be benign... (Malaysia, Chinese, 43 years, T1, S1)

I also had a small lump at that time in my left breast. I thought it was a fibroadenoma since there were no changes in shape, skin or indented nipple. But the lump grew in size over time... (Singapore, Malay, 46 years, T3, S3)

\section{Information from online resources}

Four women searched and read online information about their symptoms, and decided not to seek medical advice until their symptoms worsened.

When I found the lump in my breast, I went to search the internet. The information on the websites said, if the lump is mobile, then it is not cancerous, 'benign'. I did not worry about it. (Singapore, Chinese, 25 years, T1, S3)

It said on the health promotion board's website that there are different types of breast cancer and that some lump are not cancerous, my lump did not seem to fall into any of the categories. I left it for so many months until there was pain. (Malaysia, Malay, 35 years, T4, S4)

\section{Attribution of symptoms to cancer}

Nine women had rare symptoms. These women spoke of how they never contemplated cancer to be the cause of their symptoms, which to them appeared to be due to a 'simple' condition or not associated with other health conditions. These women talked about how they managed the symptom.

I did not know the symptom; I thought it was a pimple. I tried to clean it myself and rub cream on it. It became bigger, it looked red like a cherry and there was pus. I was confused. (Singapore, Malay, 52 years, S2, T2)

I saw the soft gel like patch on my nipple. I did not know it was breast cancer. I observed the patch until it hardened around the nipple. I would not have known it was cancer if I didn't have my usual clinic check-up. (Malaysia, Indian, 47 years, T1, S1)

I thought it was a piece of 'bone' on my chest since it was really hard. I was not ill. I was well and healthy. Then it grew into a lump. (Singapore, Chinese, 65 years, T1, S1)

\section{Fear of positive diagnosis and treatment}

Two women who had a fatalistic view about cancer delayed seeking help; they talked about how they lost hope after discovery and how this led to fear of diagnosis and treatment. Another two women adopted a 'wait and see' attitude, and procrastinated in seeking help for their symptoms, and finally went to the doctor after the lump had grew larger.

It's scary, no one can be saved. We die when we have cancer. I thought then I will just let the cancer ran its cause naturally. (Malaysia, Indian, 60 years, T4, S4)

This kind of illness is very scary. Even if it's in the early stages, it is difficult to be cured. So I dragged for about three months and some more. I was so afraid if it's a malignant tumour. (Singapore, Chinese, 39 years, T2, S2)

I found a small hard lump but waited for 6 months before seeing the doctor. I told my husband when I discovered the lump and he asked me to see the doctor but I waited. I was afraid of the diagnosis. I saw the doctor when the lump became size of an egg. (Malaysia, Chinese, 47 years, T3, S3)

I was worried about the treatment. I debated with myself many times when I discovered the lump. (Singapore, Chinese, 39 years, T3, S4)

\section{Fear of hospitalisation}

Two Malaysian women talked about their fear of being admitted into a 'government' hospital. Government hospitals are generally perceived to have a poorer quality of care and service, compared to private hospitals, even though the reality may be otherwise. These women were concerned about not being taken care of by adequately trained staff and the loneliness of not having their children with them when they were in hospital.

I did not want to go to government hospital, facilities are not so good, have to wait quite long ... always delay like in appointment, operation ... not so good. I did not tell anyone. (Malaysia, Chinese, 61 years, T4, S4)

Did not want to be admitted into hospital because she was afraid that she will not come out again due to old age, lonely in the hospital. (Singapore, Malay, 82 years, $\mathrm{T} 2, \mathrm{~S} 2)$

In Singapore, an elderly woman kept her symptoms from her son and daughter-in-law because she did not want to be admitted into the hospital. For her, it could be the last place she would live-that she would not be able to recover from her condition.

It a place to die from this disease. I had this lump and I knew if I was admitted, I would die there. I could not tell my son, I kept this secret until it was too pain... (Singapore, Malay, 80 years, T3, S3) 
Fate; family history of breast cancer

Knowledge of family history caused two women to delay presentation for medical care, as these patients did not expect a recovery from breast cancer.

When I saw the symptom, I knew I had was breast cancer because there is a family history. Both my mum and youngest sister had died of cancer. I accepted that this was fate; it's incurable. (Malaysia, Chinese, 61 years, T4, S4)

I also have family history of cancer in my family. My mother and youngest sister both died of breast cancer. I was afraid to find out that it was cancer. (Singapore, Malay, 60 years, T3, S3)

\section{Denial that symptoms were cancer}

Many women knew about the discovery of a breast lump being a common symptom of breast cancer. Although they suspected cancer when they discovered a lump in their breast, they convinced themselves that it would disappear given time. They only sought help when the lump grew bigger.

I knew i have cancer but in denial. I went about my daily routine like normal. I did not tell anyone. I kept telling myself, it was nothing, it will go away by itself. (Singapore, Indian, 72 years, T2, S2)

I suspected it was breast cancer when I found the lump. I told my husband. He refused to believe. He was in denial. I did not want to upset him, I listened to him. (Singapore, Indian, 58 years, T4, S4)

\section{Preference for alternative and traditional medicine as first-line treatment}

Alternative and traditional medicine were preferred as the first-line choice of healthcare following experience of symptoms. Seven women (6 Malaysians and 1 Singaporean) used Chinese medicine, acupuncture treatment, traditional healing, homeopathic therapy and/or massage to 'break up' the lump.

\section{Financial problem}

Three women in Singapore and three in Malaysia reported that they deliberately avoided medical help because of their financial problems. One Malaysian patient was worried about the expensive treatment cost, especially in a private hospital, and opted not to seek medical care initially. The Singaporean patients also had concerns about the cost of treatment, the effect on their children's medical insurance, the limited extent government subsidy for treatment, and possible enrolment into clinical trials to help reduce cost of treatment.

At that time, I did not think of seeking treatment because I cannot afford private hospital fees. I decided I don't want treatment, let the cancer be. When the time comes to die, just let it be. (Malaysia, Chinese, 61 years, $\mathrm{T} 4, \mathrm{~S} 4)$
I really did not want to see the doctor when I found the lump. The treatment cost is expensive in Singapore. I have Medisave and my son also has saving. But it would be a lot of money. I waited and hope it would go away. When I finally had treatment, they told me I am qualified for government subsidy, I have no knowledge of this subsidy. Now I am in the clinical trial. (Singapore, Chinese, 65 years, T2, S2)

\section{Lower priority over celebrations and holidays}

Two women delayed seeking medical advice and attention because they were reportedly busy during festivals (eg, Chinese New Year) and weddings. The discovery of a health problem during a festive period was viewed in some communities as a sign of 'bad luck', and hence might not be accorded the attention it requires.

\section{Marital problem and children's marriage prospects}

Four women talked about the stigma in the community and their marital problems, and how this affected their decision to seek help after discovering a breast symptom.

I was preoccupied with my broken marriage and too depressed to see the doctor when I found a lump in my breast. (Malaysia, Malay, 48 years, T4, S3)

I did not want to tell anyone. I wanted to see my daughters marrying a good man. If they know I have breast cancer, my daughters will not be married. (Malaysia, Indian, 65 years, T4, S4)

I was worried about my daughter. She is very filial and capable but still single and 30 years old. I worried about her future, she will have higher risk of breast cancer, not able to find a partner in life and being a burden to her. (Singapore, Chinese, 62 years, T2, S3)

\section{Misinformed by relatives}

In Malaysia, two women were wrongly advised by their relatives: one said that the woman's lump was due to her pregnancy and another said that the patient was not in the age group at risk of breast cancer. A young patient in Singapore told her mother of her discovery and the mother told her that the patient's lump was benign.

I don't know anyone who had breast cancer. I did not expect I was having cancer when I found a hard and painless lump in my breast when I was 7 months pregnant. I asked my older sister and she said that it was milk. (Malaysia, Chinese, 34 years, T4, S3)

My husband said I was too young to have breast cancer... (Singapore, Indian, 48 years, T2, S2)

My Mum said she had a benign lump which disappeared after a while. I did not do anything about it until later... (Singapore, Chinese, 25 years, T1, S3) 


\section{Misdiagnosis by HCPs}

Three women in Malaysia recalled instances of misdiagnosis by HCPs. They said that the doctors initially told them that they had a benign lump, and that breast feeding might have caused the breast symptoms and signs. Part of this may be a result of miscommunication instead of misdiagnosis.

I found a lump and I went to see a gynaecologist because I previously had benign cysts. The doctor said it is not breast cancer because mobile lump is not cancerous. I monitored the lump until it became bigger and stagnated. I went to another doctor then. (Malaysia, Chinese, 43 years, $\mathrm{T} 1, \mathrm{~S} 1)$

I asked the doctor about the pain and swelling in my breast. He said, it's related to menstruation. (Malaysia, Indian, 47 years, T2, S2)

When I was about to deliver my baby, my breast started to swell. After i delivered my baby, the nurse came to the house and she said that the swelling was due to milk. When I went for check up during my pregnancy, I told them at the clinic that I have something like milk abscess and I felt pain. But no one said anything about cancer. Everyone said that it might be milk abscess because I was pregnant. (Malaysia, Indian, 34 years, T4, S4).

\section{DISCUSSION}

There are few differences in the presentation of breast cancer between Malaysia and Singapore in terms of pattern, knowledge and awareness of symptoms and causes, and reported barriers in seeking medical care. Our findings have implications, particularly for Singapore, a country that boasts of having the most efficient healthcare, ${ }^{17}$ and ranked 6th of WHO's best health systems in the world. ${ }^{18}$

Similar to previous evidence, ${ }^{78}$ we also found that Malaysian patients presented at later stages compared to Singaporean patients, and Malay ethnicity had the highest incidence of advanced stage cancer and delayed presentation compared to being Chinese and Indian in both countries.

Poor knowledge and awareness of breast cancer (symptoms, causes and treatment) was the underlying cause of the reported barriers to early presentation. ${ }^{13}$ In the present study, three participants reported not having heard of breast cancer and, of the participants who knew about breast cancer, not all were aware of the different symptoms of breast cancer. The perceived causes of breast cancer reported by participants also showed poor knowledge of breast cancer's risk factors. These factors had led to symptom misinterpretation; fear of diagnosis, hospital admission and treatment; wrong advice by relatives; stigmatism; use of traditional and complementary medicine; and attributing symptoms to other conditions such as breast feeding. Ultimately, this resulted in delay in help-seeking after symptom discovery.
When comparing ours to previous evidence in Singapore, it is apparent that awareness and knowledge of breast cancer has remained low. In a survey of 26885 women after the launch of the Singapore national breast screening programme in 2002, 39.7\% reported that there was very little hope of cure even if the breast cancer was detected early; $21.5 \%$ of women still present with advanced cancer despite the breast health promotion prior to the launch of the mammography programme. ${ }^{19}$ In a recent study, misconceptions about cancer were reported to be prevalent in Singapore, resulting from limited cancer knowledge. Of 480 participants, 35\% thought that cancer was fatal, $49 \%$ thought that cancer would always relapse and $71 \%$ thought that cancer was always physically painful. Further, 33\% thought that cancer screening was only for symptomatic individuals. $^{20}$ In our study, Singaporean patients reported similar causes for delayed help-seeking.

In Malaysia, we also found that knowledge of disease, treatment and outcomes delayed decision to early presentation, as reported previously. ${ }^{21-23}$ We also found that Chinese patients presented early compared to Malay patients. A recent study showed that there was an increase in the number of women presenting with early stages of cancer over time; $15.2 \%$ in the period between 1993 and $1997,21.5 \%$ in $1998-2002,24.3 \%$ in 2003-2007 and $25.2 \%$ in 2008-2011 $(\mathrm{p}<0.001) .{ }^{8}$ The authors also found that being Chinese was significantly associated with early presentation and no association was observed for Malay ethnicity; indicating that pattern of presentation by ethnicity has remained unchanged in Malaysia.

A significant finding in the present study is delay in help-seeking due to online information. A few patients based their decision to seek medical help on the information obtained from breast cancer websites. For example, the Singapore Cancer Society states that “...8 out of 10 breast lumps are benign or non-cancerous. The type of breast lump depends on the woman's age..." A similar message is posted on the authoritative Malaysian website, the Malaysian Oncology Society. In the UK, websites such as Cancer Research UK and Breast Cancer Now also state that "not all lumps are cancerous but the majority are benign." 2425 Research is needed to assess the quality of online breast cancer information in Malaysia and Singapore, and ascertain the association between online information and helpseeking behaviour for breast symptoms.

Relatives have both, positive and negative influences, on women's health decisions and behaviour. The role of relatives in motivating breast screening has been reported. ${ }^{26}$ However, we also found that family members, work colleagues and friends, contributed to delayed presentation when they wrongly attributed symptoms to a previous personal experience of benign conditions or encouraged the use of alternative or traditional medicine as the first line of treatment. The impact of family and friends on women's health decision-making requires more investigation. 
More initiatives are needed to improve awareness and knowledge, in Singapore and Malaysia, on breast cancer and symptoms, particularly on the relevance of rare symptoms, prevention through BSE and mammography, and treatment, in order to improve early presentation, diagnosis and timely treatment. In Malaysia, efforts are also needed to improve public confidence in the quality of care and service provided by government hospitals, and to inform the public that advanced oncology treatment facilities are also housed in government and in public hospitals, and not exclusively in private hospitals. In Malaysia, there is a general perception that government or state-run hospitals are poorly staffed with lack of experts and facilities in the country, and there is also poor awareness that specialised breast cancer units are housed in state-run hospitals, not in private hospitals.

The strength of our study lies in the qualitative research method employed; this method is novel in the context of a multicentre, comparative study involving centres located in different countries. Our large sample size also provided a rich data set and findings that allowed an investigation into the presentation of breast cancer in three ethnic groups that share many common beliefs and practices, and consist of people living in two different countries. Our findings in Malaysia have limited generalisation as our study site, University of Malaya Medical entre, which provides care for $<5 \%$ of patients with breast cancer in the country, is located in a middle-income area and mainly serves this community. However, although the NUH Singapore provides care to approximately $20-25 \%$ of all patients with breast cancer in the country, it is possible to generalise our findings in Singapore, given the equitable distribution of healthcare services and resources across the country.

\section{Author affiliations}

${ }^{1}$ Faculty of Medical Science, Anglia Ruskin University, Cambridge, UK

${ }^{2}$ Gallup International, London, UK

${ }^{3}$ Saw Swee Hock School of Public Health, National University of Singapore, Singapore, Singapore

${ }^{4}$ Department of Surgery, National University Health System, Singapore, Singapore

${ }^{5}$ Faculty of Medicine and Health Sciences, University of United Arab Emirates, Al Ain, United Arab Emirates

${ }^{6}$ Social Preventive Medicine Department, Faculty of Medicine, University of Malaya, Kuala Lumpur, Malaysia

${ }^{7}$ Department of Surgery, Faculty of Medicine, University of Malaya Medical Centre, Kuala Lumpur, Malaysia

Acknowledgements This article is the research outcome of the UK-Southeast Asia-Middle East (UK-SEA-ME) Psychosocial-Cultural Cancer Research Network. ${ }^{22}$ The authors are grateful to all the participants and to Jenny Liu $(\mathrm{JL})$, who interviewed participants in Singapore.

Contributors The project was designed and developed by JNWL. CWQN, RM and JL interviewed the participants. RM, NAT, LS and CWQN performed the first level analysis. JNWL and BP conducted the second level, in-depth analysis and interpretation. JNWL wrote the first draft. All the authors reviewed and approved the final version.

Funding This study was supported by the Worldwide Universities Network (FIRS-DVPSRY 374001), Ministry of Higher Education of Malaysia's High Impact Research grant (UM.C/HIR/MOHE/06-2011) and the National
University of Singapore Global Asia Institute (Initiative to Improve Health in Asia 2011)

\section{Competing interests None declared.}

Ethics approval Ethics approvals were obtained from the University of Malaya Medical Ethics Committee (Malaysia); and from the Singapore National Healthcare Group Domain Specific Review Board.

Provenance and peer review Not commissioned; externally peer reviewed.

Data sharing statement Additional data from anonymised transcripts are available by emailing jennifer.lim@anglia.ac.uk.

Open Access This is an Open Access article distributed in accordance with the Creative Commons Attribution Non Commercial (CC BY-NC 4.0) license, which permits others to distribute, remix, adapt, build upon this work noncommercially, and license their derivative works on different terms, provided the original work is properly cited and the use is non-commercial. See: http:// creativecommons.org/licenses/by-nc/4.0/

\section{REFERENCES}

1. Jara-Lazaro AR, Thilagaratnam S, Tan PH. Breast cancer in Singapore: some perspectives. Breast Cancer 2010;17:23-8.

2. Ferlay J, Soerjpmataram I, Dikshit R, et al. Cancer incidence and mortality worldwide: sources, methods and major patterns in GLOBOCAN 2012. Int J Cancer 2015;136:E359-86.

3. Wang S. The Singapore National Breast Screening Programme: principle and implementation. Ann Acad Med Singapore 2003:32:466-76.

4. Dahlui M, Ramli S, Bulgiba AM. Breast Cancer prevention and control programs in Malaysia. Asian Pac J Cancer Prev 2011:12:1631-4.

5. Seow A, Koh WP, Chia KS, et al. Singapore Cancer Registry Report NO. 6. Trends in cancer incidence in Singapore 1968-2002. http:// www.hpd.gov.sg/uploadedFiles/HPB_Online/Publications/Report 1968_2002.pdf (accessed 18 Mar 2011).

6. Lim GCC, Yahaya H. Second Report of the National Cancer Registry Cancer Incidence in Malaysia 2003. http://www.radiologymalaysia. org/archive/ncr/2ndncr.pdf (accessed on 18 Mar 2011).

7. Saxena N, Hartman M, Bhoo-Pathy N, et al. Breast cancer in South East Asia: comparison of presentation and outcome between a middle income and a high income country. World $J$ Surg 2012;36:2838-46.

8. Bhoo-Pathy $\mathrm{N}$, Hartman $\mathrm{M}$, Yip $\mathrm{CH}$, et al. Ethnic differences in survival after breast cancer in South East Asia. PLOS ONE 2012;7: e30995.

9. Agarwal G, Pradeep PV, Aggarwal V, et al. Spectrum of breast cancer in Asian women. World J Surg 2007;31:1031-40.

10. Ramirez AJ, Westcombe AM, Burgess CC, et al. Factors predicting delayed presentation of symptomatic breast cancer: a systematic review. Lancet 1999;353:1127-31.

11. Alhurishi S, Lim JNW, Potrata $B$, et al. Factors influencing late presentation for breast cancer in the Middle East: a systematic review. Asian Pac J Cancer Prev 2011;12:1597-1600.

12. Sharma K, Costas A, Shulman LN, et al. A systematic review of barriers to breast cancer care in developing countries resulting in delayed patient presentation. $J$ Oncol 2012;2012:121873.

13. Jones $\mathrm{C}$, Maben J, Jack RH, et al. A systematic review of barriers to early presentation and diagnosis with breast cancer among black women. BMJ Open 2014;4:e004076.

14. Lim JNW. The UK-SEA-ME Psychosocial-Cultural Cancer Research Network: setting the stage for applied qualitative research on cancer health behaviour in Southeast Asia and the Middle East. Asian Pac $J$ Cancer Prev 2011;12:1627-9.

15. Boyatzis R. Transforming qualitative information. London: Sage, 1998

16. Guest G, MacQueen KM, Namey E. Introduction to applied thematic analysis, Applied Thematic Analysis. London: SAGE Publications, 2012.

17. Bloomberg Business, Most Efficient Health Care 2014. http://www. bloomberg.com/visual-data/best-and-worst//most-efficient-healthcare-2014-countries (accessed 27 Aug 2015).

18. WHO. The World Health Report 2000: Health Systems: Improving Performance. World Health Organisation, 2000:154

19. Tan EY, Wong HB, Ang BK, et al. Locally advanced and metastatic breast cancer in a tertiary hospital. Ann Acad Med Singapore 2005;34:595-7.

20. Ong CS, Ooi G, Tan XQ, et al. Prevalence of limited cancer knowledge in Singaporeans, its determinants and association with cancer screening. Prev Med 2010;50:304-5. 
21. Norsa'adah B, Rahman MA, Rampal KG, et al. Understanding barriers to Malaysian woman with breast cancer seeking help. Asian Pac J Cancer Prev 2012;13:3723-30.

22. Norsa'adah B, Rampal KG, Rahman MA, et al. Diagnosis delay of breast cacner and its associated factors in Malaysian women. BMC Cancer 2011;11:141.

23. Taib NA, Low WY, Yip $\mathrm{CH}$. A grounded explanation of why women present with advanced breast cancer. World J Surg 2014;38:1676-84.
24. CRUK Breast cancer symptoms. http://www.cancerresearchuk.org/ (accessed 10 Jul 2015)

25. Breast Cancer Now. http://breastcancernow.org/about-breast-cancer/ what-are-the-signs-and-symptoms-of-breast-cancer? (accessed 10 Jul 2015).

26. Seow A, Straughan PT, Ng EH, et al. Factors determining acceptability of mammography in an Asian population: a study among women in Singapore. Cancer Causes Control 1997;8:771-9. 